\begin{tabular}{|c|c|c|c|c|c|}
\hline Study & $\begin{array}{l}\text { Total } \\
\text { Pts. }\end{array}$ & $\begin{array}{l}1 \mathrm{~mm} \\
\text { ST } \downarrow\end{array}$ & $\begin{array}{l}\text { T-Wave } \\
90^{\circ} \\
\text { Change }\end{array}$ & $\begin{array}{l}\text { T-Wave } \\
180^{\circ} \\
\text { Change }\end{array}$ & Provocation \\
\hline \multicolumn{6}{|l|}{ Past studies } \\
\hline Bellet \& Roman 8 & 1,096 & 0.3 & - & 5 & Position \\
\hline Golden et al9 & 72 & - & 1 & 1 & Hyperventilation \\
\hline $\begin{array}{l}\text { Wasserburger } \\
\text { et al } 10\end{array}$ & 350 & - & - & 10 & Hyperventilation \\
\hline \multicolumn{6}{|l|}{ Present study } \\
\hline \multirow[t]{3}{*}{ Bertolet et al } & 100 & 6 & 23 & 8 & Position \\
\hline & 100 & 3 & 10 & 2 & Hyperventilation \\
\hline & 100 & 2 & 7 & 4 & Valsalva \\
\hline
\end{tabular}

mal baseline. However, no ST-segment depression $\geq 1$ $\mathrm{mm}$ was noted.

Our study demonstrates that ST-segment changes on AEM can be induced by position changes, hyperventilation or the Valsalva maneuver in almost one third of patients chosen for an electrocardiogram with a normal or near normal ST-segment baseline; however, ischemictype ST-segment depression of $1 \mathrm{~mm}$ could be demonstrated in only $4 \%$. ST-segment elevation $\geq 1 \mathrm{~mm}$ from an isoelectric baseline also was an infrequent occurrence. Twave axis shifts of $180^{\circ}$ were noted in $11 \%$ of patients after the physiologic maneuvers. Electrode shifts of $1 \mathrm{~cm}$ were more likely to induce ST-segment shifts from an abnormal baseline than from an isoelectric one; however, no ST-segment depression $\geq 1 \mathrm{~mm}$ was detected, regardless of the baseline.

This is the first study that examines the effects of various physiologic maneuvers on the electrocardiogram of cardiac patients as recorded by AEM. Deanfield et al ${ }^{7}$ used AEM to screen for ischemic-type electrocardiographic changes after postural variations in 100 normal volunteers. There were no episodes of ST-segment depression $\geq 1 \mathrm{~mm}$, only 1 episode of ST-segment elevation $\geq 1 \mathrm{~mm}$, and 2 episodes of $180^{\circ} \mathrm{T}$-wave axis shift. Some previous studies of cardiac patients using other detection methods are compared with the present study in Table II. In all, these past studies demonstrated ischemic-type ST- segment and T-wave changes in 0.3 and $1 \%$ of patients, respectively.

Screening for electrocardiographic changes induced by physiologic maneuvers is time- and labor-intensive for electrocardiographic technicians. However, we believe this practice should continue, because the results obtained may have an important role in the interpretation of ST-segment changes thought to be due to myocardial ischemia. Many of our patients manifested some STsegment or T-wave changes during physiologic activities, which increased when the baseline was abnormal. These ST-segment and T-wave shifts (which alone may be insignificant) may be additive to other stimuli causing minor electrocardiographic changes resulting in the incorrect interpretation of myocardial ischemia. If AEM is to be performed for the detection of ischemic ST-segment changes, care should be taken to exclude those subjects who develop ischemic-type but artifactual electrocardiographic changes merely with changes of position or misplacement of the lead.

1. Deanfield JE, Shea $M$, Riberio $P$, Landsheere $C M$, Wilson RA, Horlock $P$, Selwyn AP. Transient ST-segment depression as a marker of myocardial ischemia during daily life. Am J Cardiol 1984;54:1195-1200.

2. Schang SJ, Pepine CJ. Transient asymptomatic S-T segment depression during daily activity. Am $J$ Cardiol 1977;39:396-402.

3. Imperi GA, Lambert CR, Coy K, Lopez L, Pepine CJ. Effects of titrated betablockade (metoprolol) on silent myocardial ischemia in ambulatory patients with coronary artery disease. Am J Cardiol 1987;60:519-524.

4. Hill JA, Gonzalez JI, Kolb R, Pepine CJ. Effects of atenolol alone, nifedipine alone and their combination an ambulant myocardial ischemia. Am J Cardiol 1991;67:671-675.

5. Mulcahy D, Keegan J, Cunningham D, Quyyumi A, Crean P, Park A, Wright C, Fox K. Circadian variation of total ischemic burden and its alteration with antianginal agents. Lancet 1988;2:755-759.

6. Hill JA, Bertolet BD, Duran AD, Boyette A, Queffelec D, Pepine CJ. An ambulatory ECG monitoring approach to the problems of ischemia-guided care. Journal of Ambulatory Monitoring 1991;4:175 185.

7. Deanfield JE, Riberio P, Oakley K, Krikler S, Selwyn AP. Analysis of STsegment changes in normal subjects: implications for ambulatory monitoring in anginal pectoris. Am I Cardiol 1984;54:1321-1325.

8. Bellet S, Roman L. The effect of exercise on postural changes in the electrocardiogram. Circulation 1966;33:117-123.

9. Golden GS, Golden LH, Beerel FR. Hyperventilation-induced T-wave changes in the limb lead electrocardiogram. Chest 1975;67:123-125.

10. Wasserburger RH, Siebecker KL, Lewis WC. The effect of hyperventilation on the normal adult electrocardiogram. Circulation 1956;13:850-855.

\title{
Differentiation of Ventricular Tachycardia from Ventricular Fibrillation Using Intraventricular Electrogram Morphology
}

Lorenzo A. DiCarlo, MD, Janice M. Jenkins, PhD, Stuart A. Winston, DO, and Catherine Kriegler, BSEE, with the technical assistance of Judy Jaffke, RT(R) and Kathy Matney, RN

mplantable antitachycardia devices are now capable of providing "ramp" therapy including antitachycardia pacing and low- and high-energy cardioversion for sus-

From the Medical Computing Laboratory, Department of Electrical Engineering and Computer Science, and School of Medicine, University of Michigan, Ann Arbor; and the Michigan Heart and Vascular Institute and Cardiac Electrophysiology Laboratory, St. Joseph Mercy Hospital, Ann Arbor, Michigan. Dr. DiCarlo's address is: Reichert Health Building, R-3003, P.O. Box 994, Ann Arbor, Michigan 48106. This study was supported in part by Grants BCS-8909042 and EID9023514 from the National Science Foundation, Washington, D.C. Manuscript received February 20, 1992; revised manuscript received and accepted April 20, 1992. tained ventricular tachycardia (VT) in addition to defibrillation of ventricular fibrillation (VF)..$^{1,2}$ Appropriate therapy, however, is dependent on correct identification of VT and VF. Because of variations in ventricular electrographic amplitude during VF, currently implanted devices are unable to consistently detect consecutive ventricular depolarizations during VF. ${ }^{3}$ As a result, the rate criteria for VF detection may sometimes overlap with the rate criteria used for VT detection. Morphologic analysis of intracavitary ventricular electrograms using correlation waveform analysis has been demonstrated in previous studies to be effective in discriminating normal sinus 
rhythm from VT, paroxysmal bundle branch block of supraventricular origin, and retrograde atrial activation. ${ }^{4-7}$ Whether VF is distinguishable from sinus rhythm and VT with a similar method has not been determined. This study examined whether VT and VF can be distinguishable from sinus rhythm and from each other by correlation waveform analysis of intracavitary ventricular electrograms.

Twelve consecutive patients were evaluated while undergoing routine cardiac electrophysiologic studies. Distal bipolar (1 to $500 \mathrm{~Hz}$ ) intraventricular electrograms were recorded from an electrode catheter positioned in the right ventricular apex during sinus rhythm, monomorphic $V T$ induced by programmed electrical stimulation, and VF induced by programmed stimulation or alternating current. Ventricular electrograms were recorded on FM magnetic tape and digitized subsequently on a PC at a sampling rate of $1,000 \mathrm{~Hz}$. The programs for digitizing and waveform analysis were written in $C$ and assembly language. $A$ digital differentiator was used to detect each of the individual intracardiac electrograms. A template was created from a 15-second passage of sinus rhythm for correlation waveform analysis of subsequent 15- to 30-second passages of sinus rhythm, VT and VF. Correlation waveform analysis was used as a statistical measure of the similarity or dissimilarity of the waveform under analysis with the sinus rhythm template. The correlation coefficient was defined as:

$$
\rho=\frac{\sum_{i=1}^{i=N}\left(t_{i}-\bar{t}\right)\left(s_{i}-\bar{s}\right)}{\sqrt{\sum_{k=1}^{k=N}\left(t_{k}-\bar{t}\right)^{2}} \sqrt{\sum_{k=1}^{k=N}\left(s_{k}-\bar{s}\right)^{2}}}
$$

where $t_{k}=$ the template points, $S_{k}=$ the signal points to be processed, $\bar{t}=$ the average value of the template points, $\bar{s}=$ the average value of the signal points, $N=$ the number of points in the template, and $\rho=$ the index of merit. The value of the correlation coefficient therefore fell between \pm 1 such that identical waveforms had a value +1 , waveforms which were inverses of one another had a value of -1 , and all other, dissimilar waveforms had values between +1 and -1 . A patientspecific window was chosen during creation of the sinus rhythm template to include depolarization only and to exclude the potentially confounding repolarization injury current caused by the acute placement of the electrode catheters. This window size was imposed on all subsequently analyzed electrograms. The template was aligned with the trigger point of the electrogram under analysis, and then shifted a maximum of $10 \mathrm{~ms}$ in both directions in order to maximize the alignment of the 2 waveforms. The magnitude of the variance of cycle-tocycle correlation waveform analysis was then used as a discriminant function for $V T$ and $V F$.

Table I summarizes the results for all 12 patients. The types of electrograms analyzed are illustrated in Figures 1 and 2. The window sizes of the analyzed electrograms ranged from 52 to $106 \mathrm{~ms}$. Mean correlation coefficient separated sinus rhythm from VT in 10 of 12
TABLE I Results of Correlation Waveform Analysis for Discriminating Ventricular Tachycardia from Ventricular Fibrillation

\begin{tabular}{|c|c|c|c|c|c|c|}
\hline \multirow[b]{2}{*}{$\begin{array}{l}\text { Pt. } \\
\text { No. }\end{array}$} & \multicolumn{2}{|c|}{ Sinus Rhythm } & \multicolumn{2}{|c|}{$V T$} & \multicolumn{2}{|c|}{ VF } \\
\hline & $\begin{array}{l}\text { Mean } \\
\text { p Value }\end{array}$ & SD & $\begin{array}{l}\text { Mean } \\
\text { p Value }\end{array}$ & SD & $\begin{array}{l}\text { Mean } \\
\text { p Value }\end{array}$ & SD \\
\hline 1 & 0.986 & 0.008 & 0.852 & 0.115 & 0.714 & 0.221 \\
\hline 2 & 0.987 & 0.006 & 0.836 & 0.072 & 0.355 & 0.348 \\
\hline 3 & 0.995 & 0.003 & -0.108 & 0.097 & 0.499 & 0.382 \\
\hline 4 & 0.970 & 0.003 & 0.848 & 0.017 & 0.405 & 0.453 \\
\hline 5 & 0.980 & 0.006 & 0.882 & 0.041 & 0.429 & 0.493 \\
\hline 6 & 0.962 & 0.020 & 0.641 & 0.047 & 0.625 & 0.408 \\
\hline 7 & 0.995 & 0.002 & 0.925 & 0.007 & 0.650 & 0.433 \\
\hline 8 & 0.990 & 0.021 & 0.969 & 0.013 & 0.347 & 0.432 \\
\hline 9 & 0.984 & 0.011 & 0.868 & 0.022 & 0.228 & 0.490 \\
\hline 10 & 0.977 & 0.049 & 0.960 & 0.018 & 0.881 & 0.092 \\
\hline 11 & 0.959 & 0.024 & 0.040 & 0.177 & 0.162 & 0.499 \\
\hline 12 & 0.996 & 0.003 & 0.870 & 0.087 & 0.313 & 0.718 \\
\hline
\end{tabular}

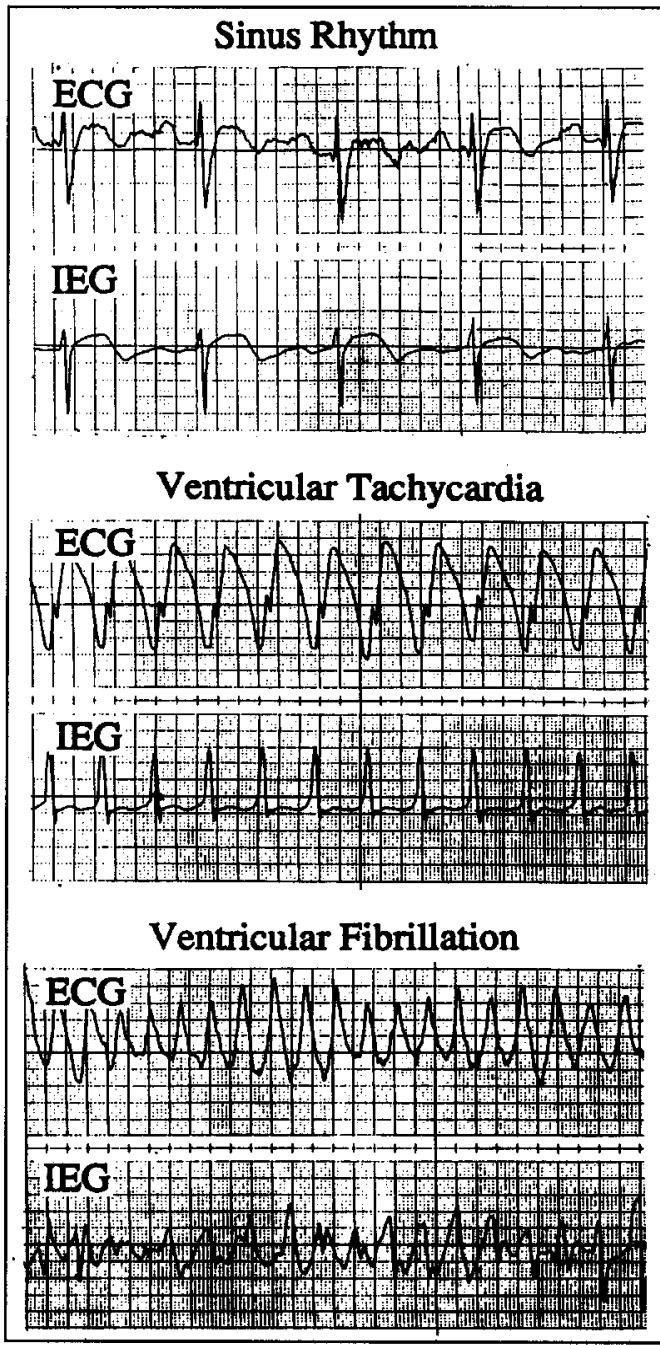

FICURE 1. Examples of aurface eloctrocarlogrephle (ECG) and ditad bipoler intraventrictior electrograms (IEG) of pa-

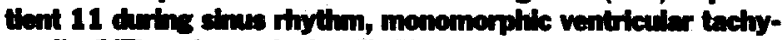
cardia (VT) and ventriculer filurilation (VF). The stfierence in moen correlation coofilicient from cerrelation wavelorm anclyds of sinus thythm $(0.959)$ effferentiated it from VT $(0.040)$ and VF $(0.162)$. The varlance of VT $(0.177)^{2}$ differentiated $i$ from VF (0.499)2. 
patients (83\%) and sinus rhythm from VF in all 12 patients (100\%). The range (and means) for standard deviation(s) were 0.004 to 0.049 (0.013) for sinus rhythm, 0.007 to $0.177(0.059)$ for VT, and 0.092 to $0.718(0.414)$ for VF. For each of the 12 patients, the individual variances for $V T$ and $V F$ were significantly different ( $F$ test, $p<0.0001$ ). A threshold midway between the average variance in VT and $V F$, respectively, was a successful discriminant in 11 of 12 patients $(92 \%)$.

The primary method for tachycardia detection of VT and VF by currently implanted devices has been based on timing information derived from heart rate, including an abrupt increase in heart rate, detection of a rate that exceeds an arbitrary minimum, and observation of a stable RR interval during the tachycardia. ${ }^{8}$ However, such algorithms lack specificity for VT and VF recognition.

The complementary use of time and frequency domain analysis has been proposed for VT and VF detection. $4-7,10-14$ The only method now used in implanted
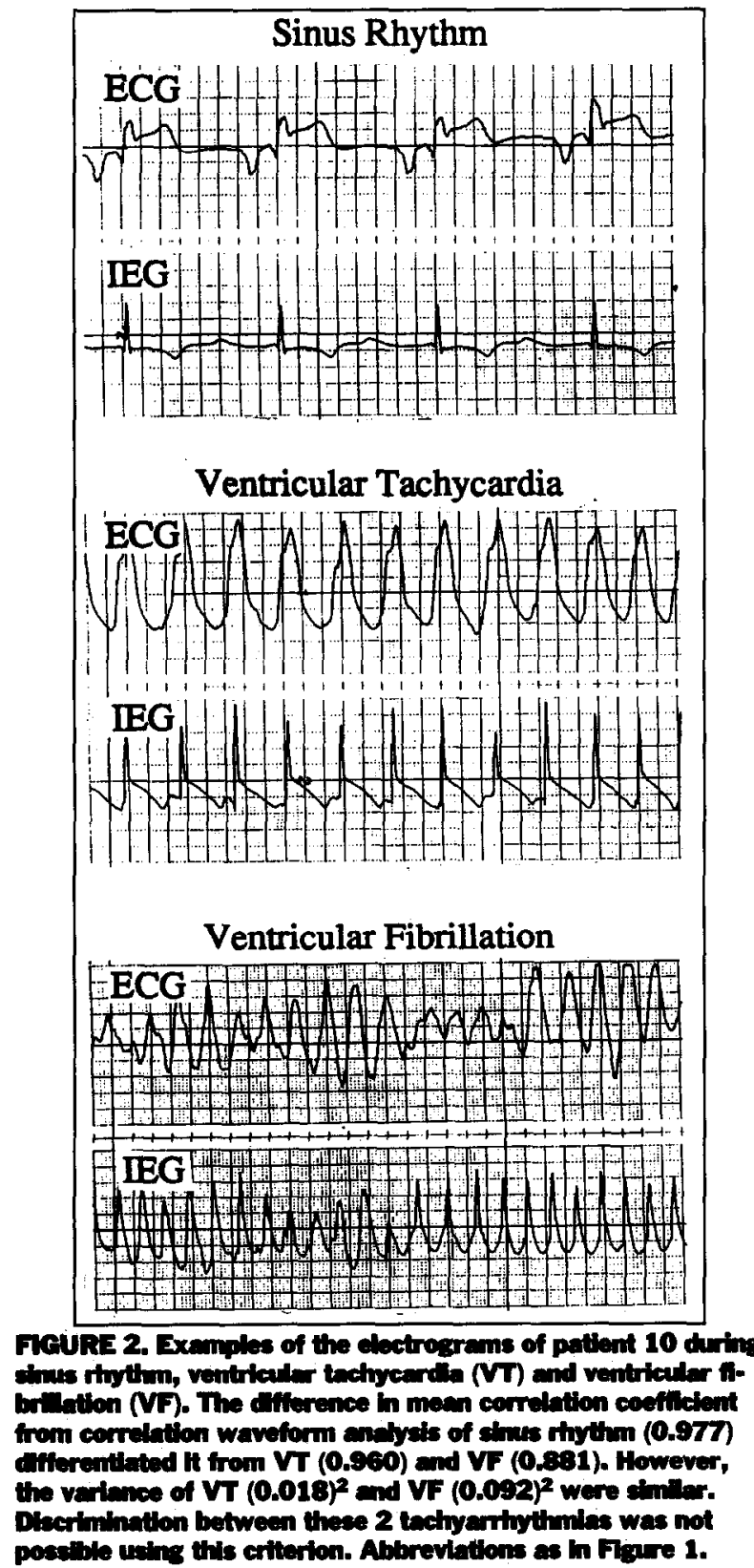

devices for VF detection - probability density function $^{9}$ - has had limited applicability for patients who experience both recurrent VT and VF. Previous studies have demonstrated the efficacy of correlation waveform analysis in detecting VT when compared with other proposed time and frequency domain analyses of individual bipolar intraventricular electrograms. ${ }^{4-7}$ The results of this study suggest that a similar time domain analysis of intraventricular bipolar electrograms may also be useful in discriminating VF from sinus rhythm as well as from more organized and more stable monomorphic VT.

The present study had several limitations. The recordings analyzed were from supine patients during clinical electrophysiologic studies. No effort was made to optimize any filter characteristics to improve alignment. The impacts of changes in position, hydration and vascular tone were not examined. Changes in electrogram amplitude that might occur during everyday activity of a patient with a permanent lead also remain unknown.

Although correlation waveform analysis has the potential advantages of being independent of electrogram amplitude and baseline fluctuations, its incorporation in currently available, implantable microprocessors may prove to be impractical because of its computational demands. Further work is necessary to determine whether other, less computationally demanding time domain methods are similarly effective in detecting and distinguishing VT and VF. ${ }^{15}$

1. Mirowski M, Reid PR, Mower MM, Watkins L Jr, Gott VL, Schauble JF Langer A, Heilman MS, Kolenik SA, Fischell RF, Weisfeldt ML. Termination of malignant ventricular arrhythmias with an implanted automatic defibrillator in human beings. $N$ Engl J Med 1980;303:322-324.

2. Hook BG, Marchlinski. Value of ventricular electrogram recordings in the diagnosis of arrhythmias precipitating electrical device therapy. J Am Coll Cardiol 1991;17:985-990.

3. Santel D, Mehra R, Olson W, Bardy G. Integrative algorithm for detection of ventricular tachyarrhythmias from the intracardiac electrogram. IEEE Comp Cardiol 1987:175-177.

4. Lin D, DiCarlo LA, Jenkins JJ. Identification of ventricular electrograms: analysis of time and frequency domain patterns. PACE 1988;11:1592-1606. 5. Throne RD, Jenkins JM, Winston SA, DiCarlo LA. Use of tachycardia templates for recognition of recurrent monomorphic ventricular tachycardia. IEEE Comp Cardiol 1989:171-174.

6. Throne RD, DiCarlo LA, Jenkins, Winston SA. Paroxysmal bundle branch block of supraventricular origin: a possible source of misdiagnosis in detecting ventricular tachycardia using time-domain analysis of intraventricular electrograms. PACE 1990;13:453-468.

7. Throne RD, Jenkins JJ, Winston SA, Finelli CJ, DiCarlo LA. Discrimination of retrograde from anterograde atrial activation using intracardiac electrogram waveform analysis. $P A C E$ 1989;12:1622-1630.

8. Spurrell RAJ, Nathan AW, Camm AJ. Clinical experience with implantable scanning tachycardia reversion pacemakers. PACE 1984;7:1296-1300.

9. Langer $\mathrm{A}$, Heilman MS, Mower MM, Mirowski M. Considerations in the development of the automatic implantable defibrillator. Med Instr 1976;10: 163-167.

10. Langberg JJ, Gibb WJ, Auslander DM. Griffin JC. Identification of ventricular tachycardia with the use of the morphology of the endocardial electrogram. Circulation 1988;77:1363-1369.

11. Pannizzo $F$, Furman $S$. Frequency spectra of ventricular and sinus rhythm in human intracardiac electrograms - application to tachycardia detection for cardiac pacemakers. IEEE Trans Biomed Eng 1988;35:421-425.

12. Ripley KL, Bump TE, Arzbaecher RC. Evaluation of techniques for recognition of ventricular arrhythmias by implanted devices. IEEE Trans Biomed Eng 1989;36:618-624.

13. Davies DW, Wainwright RJ, Tooley MA, Lloyd D, Nathan AW, Spurrel RAJ. Detection of pathological tachycardia by analysis of electrogram morphology, PACE 1986;9:200-208.

14. Ropella KM, Baerman JM, Sahakian AV, Swiryn S. Differentiation of ventricular tachyarrhythmias. Circulation 1990;82:2035-2043.

15. Throne RD, Jenkins JJ, DiCarlo LA. A comparison of four new time-domain techniques for discriminating monomorphic ventricular tachycardia from sinus rhythm using ventricular waveform morphology. IEEE Trans Biomed Eng 1991;38:561-570. 